\title{
Leptin enhances migration of human papillary thyroid cancer cells through the PI3K/AKT and MEK/ERK signaling pathways
}

\author{
SHIH-PING CHENG ${ }^{1,4,5}$, PEN-HUI YIN ${ }^{2}$, YI-CHIUNG HSU ${ }^{6}$, YUAN-CHING CHANG ${ }^{1}$, \\ SHIH-YUAN HUANG ${ }^{1}$, JIE-JEN LEE ${ }^{1,4,5}$ and CHIN-WEN CHI ${ }^{2,3}$
}

\author{
${ }^{1}$ Department of Surgery, Mackay Memorial Hospital, Taipei; ${ }^{2}$ Department of Medical Research and Education, Taipei \\ Veterans General Hospital, Taipei; ${ }^{3}$ Department and Institute of Pharmacology, School of Medicine, National Yang-Ming \\ University, Taipei; ${ }^{4}$ Department of Pharmacology, Taipei Medical University, Taipei; ${ }^{5}$ Department of Medicine, \\ Mackay Medical College, New Taipei City; ${ }^{6}$ Institute of Statistical Science, Academia Sinica, Taipei, Taiwan, R.O.C.
}

Received May 30, 2011; Accepted June 9, 2011

DOI: $10.3892 /$ or.2011.1388

\begin{abstract}
The incidence of thyroid cancer has remarkably increased in recent years. Epidemiologic data suggest that obesity is associated with an increased incidence of several types of malignancies, including thyroid cancer. Leptin, an adipocyte-derived cytokine, has been shown to be involved in cancer development and progression. We previously demonstrated that papillary thyroid cancer expressing leptin receptor and/or leptin has a higher incidence of lymph node metastasis. In this study, we investigated the effects of leptin on cell migration in $\mathrm{K} 1$ and B-CPAP papillary thyroid cancer cells. Expression of leptin receptor was observed in both cell lines. Leptin enhanced the migratory activity significantly in a dose-dependent manner. We showed that leptin induced AKT and extracellular signal-regulated kinase (ERK) phosphorylation. Inhibition of phosphatidylinositol 3-kinase and ERK activation using pharmacological inhibitors effectively blocked leptin-induced migration of K1 and B-CPAP cells. Taken together, this study provides new mechanistic evidence for a role of leptin in the regulation of papillary thyroid cancer progression by stimulating tumor cell migration.
\end{abstract}

\section{Introduction}

Obesity is a major global health problem and has reached epidemic levels worldwide. There is convincing evidence from epidemiological data showing that obesity increases the risk

Correspondence to: Professor Jie-Jen Lee, Department of Surgery, Mackay Memorial Hospital, 92, Sec 2, Chung-Shan North Road, Taipei 10449, Taiwan, R.O.C.

E-mail: surg.mmh@gmail.com

Professor Chin-Wen Chi, Department of Medical Research and Education, Taipei Veterans General Hospital, 201, Sec 2, Shih-Pai Road, Taipei 11217, Taiwan, R.O.C.

E-mail: cwchi@vghtpe.gov.tw

Key words: leptin, thyroid cancer, cell migration, PI3K/AKT, MAPK for several types of cancer (1-3). Overweight-related changes of the adipose tissue lead to insulin resistance, chronic inflammation, and altered secretion of adipokines (4). These mechanisms synergistically contribute to cancer development and progression. Excess body weight is positively correlated with serum levels of adipocyte-derived obesity hormone, leptin (5). Leptin was originally discovered as a hormone regulating appetite and energy expenditure. However, recent studies indicate that leptin has mitogenic, anti-apoptotic, proinflammatory, and angiogenic properties and plays an important role in the link between obesity and cancer $(6,7)$.

Leptin is a $16 \mathrm{kDa}$ polypeptide encoded by the obese (OB) gene (8). Leptin exerts its physiological and pathophysiological effects by binding to the trans-membrane leptin receptor (9). Several isoforms of leptin receptor resulting from alternative splicing share an identical $\mathrm{N}$-terminal ligand-binding domain but differ at the C-terminal region (5). The long isoform with an extended intracellular domain containing motifs required for the interaction with other proteins and subsequent signaling pathway activation is the most important functional receptor. Leptin promotes cell proliferation of breast (10), hepatocellular (11), prostate (12), and endometrial (13) carcinoma cells through the phosphoinositide 3-kinase (PI3K)/AKT and extracellular signal-regulated kinases (ERK) 1/2 pathways. Moreover, leptin has been shown to stimulate migration and/or invasion of breast (14), hepatocellular (15), prostate (16), endometrial (13), and colon (17) carcinoma cells similarly via the activation of the PI3K/AKT and ERK 1/2 signaling cascades.

The increased prevalence of obesity is accompanied with the rising incidence of thyroid cancer (18). A comprehensive systematic review found that an increase of body mass index (BMI) by $5 \mathrm{~kg} / \mathrm{m}^{2}$ was associated with increased risk of thyroid cancer in both men and women with a relative risk of 1.33 and 1.14, respectively (1). Subsequently, the French E3N study including 91,909 women confirmed a significant dose-effect relationship between BMI and thyroid cancer risk (19). At present, the mechanisms for the risk associated between obesity and thyroid cancer are poorly understood. Interestingly, serum leptin levels in patients with papillary thyroid cancer are significantly higher than BMI-matched 
control subjects (20). The leptin levels decreased after total thyroidectomy but remained higher than the control group levels. It raises the possibility that leptin may be involved in the pathogenesis of thyroid cancer.

Using immunohistochemical analysis, we and others have reported that leptin and leptin receptor were overexpressed in papillary thyroid cancer and metastatic lymph nodes $(21,22)$. Expression of leptin receptor and/or leptin in primary tumors was associated with higher incidence of lymph node metastasis. Our pilot study also suggested that leptin may modulate migration of thyroid cancer cells (23). However, Schweppe and colleagues recently showed that many of the thyroid cancer cell lines are cross-contaminated or misidentified (24). Although the CGTH-W3 cell line we previously used was not included in their report, in the present study, we re-verified key experiments and expand our prior findings by elucidation of the signal transduction pathways involving leptin-induced migration in papillary thyroid cancer cells.

\section{Materials and methods}

Cell culture and reagents. The human papillary thyroid carcinoma cell lines K1 and B-CPAP were purchased from the European Collection of Cell Cultures (ECACC, Salisbury, UK) and the German Collection of Microorganisms and Cell Cultures (DSMZ, Braunschweig, Germany), respectively. K1 cells were cultured at $37^{\circ} \mathrm{C}$ in a humidified atmosphere of $5 \% \mathrm{CO}_{2}$ in Dulbecco's modified Eagle's medium (Invitrogen/ Gibco, Carlsbad, CA) mixed with Ham's F12 (Gibco) and MCDB 105 (Sigma, St. Louis, MO) medium in 2:1:1 proportions, supplemented with $10 \%$ fetal bovine serum (FBS) and $2 \mathrm{mM}$ L-glutamine. B-CPAP cells were cultured in RPMI1640 medium (Gibco) supplemented with 10\% FBS. These cancer cells have been recently authenticated to be unique thyroid cancer cell lines (24). Recombinant human leptin for treatment was purchased from Invitrogen. PD98059 and LY294002 were obtained from Sigma.

Cell growth. Cell growth was determined using the 3-(4,5-dimethylthiazol-2-yl)-2,5-diphenyl tetrazolium bromide (MTT) colorimetric assay. Briefly, cells were seeded into 96-well plates one day before 24-h serum starvation and then incubated with leptin at indicated concentrations with or without FBS. Harvested cells were incubated in the medium containing $5 \mathrm{mg} / \mathrm{ml}$ of MTT reagent (Sigma) at $37^{\circ} \mathrm{C}$ for $4 \mathrm{~h}$. The formazan crystals converted from tetrazolium salts by viable cells were dissolved in dimethyl sulfoxide (150 $\mu \mathrm{l} /$ well) and the absorbance at $570 \mathrm{~nm}$ was measured by a microplate spectrophotometer.

Protein extraction and Western blot analysis. Whole cell lysate was prepared by resuspending cells in M-PER protein extraction reagent (Thermo Scientific/Pierce, Rockford, IL) according to the manufacturer's instructions. Cell lysates were centrifuged at $14,000 \mathrm{x}$ g for $10 \mathrm{~min}$ and supernatant collected. Protein concentration was measured using Bradford assay (Bio-Rad Laboratories, Hercules, CA). An aliquot of protein lysate $(30 \mu \mathrm{g})$ from each sample was mixed with 10X Laemmli sample buffer (Bio-Rad), and protein lysate was separated in $10 \%$ SDS-polyacrylamide gels. After transfer sample to nitrocellulose membrane, the membrane was blocked with 5\% skimmed milk for $30 \mathrm{~min}$ at room temperature. The proteins were probed with antibodies against short and long forms of leptin receptor (H-300, sc-8325; Santa Cruz Biotechnology, Santa Cruz, CA), long-form specific leptin receptor (C-20, sc-1832; Santa Cruz Biotechnology), phosphorylated AKT (pAKT-Ser ${ }^{473}$, 99271; Cell Signaling, Danvers, MA), AKT (06-608; Millipore/Upstate, Lake Placid, NY), phosphorylated ERK (pERK-Thr ${ }^{202} / \mathrm{Tyr}^{204}$, M9692; Sigma), ERK (\#4696; Cell Signaling), $\beta$-actin (A5316; Sigma), and $\alpha$-tubulin (T6074; Sigma) overnight at $4^{\circ} \mathrm{C}$. After three washes, the blots were subsequently incubated with peroxidase-conjugated secondary antibodies (Sigma) for $1.5 \mathrm{~h}$ at room temperature. The blots were visualized with enhanced chemiluminescence kit (Pierce) and Amersham Hyperfilm ECL (GE Healthcare, Piscataway, NJ).

Transwell migration assay. Cells were trypsinized, resuspended in serum-free media; then $1 \times 10^{5}$ cells were added to a 24-well chamber (\#3422; Corning Inc., Corning, NY). The upper and lower chambers were separated by a polycarbonate membrane with $8-\mu \mathrm{m}$ pore size and $10-\mu \mathrm{m}$ membrane thickness. Complete medium containing $10 \%$ FBS as the chemoattractant was added to the lower chambers. The cells were allowed to migrate for $6 \mathrm{~h}$ (B-CPAP cells) or $8 \mathrm{~h}$ (K1 cells) at $37^{\circ} \mathrm{C}$ in a humidified atmosphere containing $5 \% \mathrm{CO}_{2}$. Cells on the upper side of the membrane were removed by PBS-rinsed cotton swabs. The membrane was fixed by $100 \%$ methanol for $20 \mathrm{~min}$ at $4^{\circ} \mathrm{C}$ and stained with Giemsa solution (Sigma). Cells on the lower side of the membrane were counted using a light microscope in ten random high-power microscopic fields at x100 magnification. The mean number of migrated cells was then normalized to the vehicle control.

Wound healing assay. Cells were seeded onto a culture insert $\left(0.22 \mathrm{~cm}^{2}\right.$ growth area with a cell-free gap of $500 \mu \mathrm{m}$; ibidi $\mathrm{GmbH}$, Munich, Germany) in complete culture media. After $24 \mathrm{~h}$, the culture insert was removed allowing confluent cells to migrate across the gap. Cells were incubated in serum-free media without or with various concentrations of leptin. At $8 \mathrm{~h}$, cells were observed under microscopy and photographed.

Statistical analysis. All experiments were independently performed at least three times. Bar graphs with error bars represent mean \pm standard error of the mean (SEM). Data were analyzed using two-tailed Student's t-test. A difference of $\mathrm{P}<0.05$ between groups was considered significant.

\section{Results}

Papillary thyroid cancer cells express leptin receptor. The expression of leptin receptor in human papillary thyroid cancer cell lines was investigated by Western blotting. Using C-20 long-form specific antibody, full-length long isoform of leptin receptor was detected in K1 and B-CPAP cells (Fig. 1A). Western blot analysis using H-300 antibody against short and long forms of leptin receptor showed that both isoforms were expressed in these two cell lines (Fig. 1B). 
A

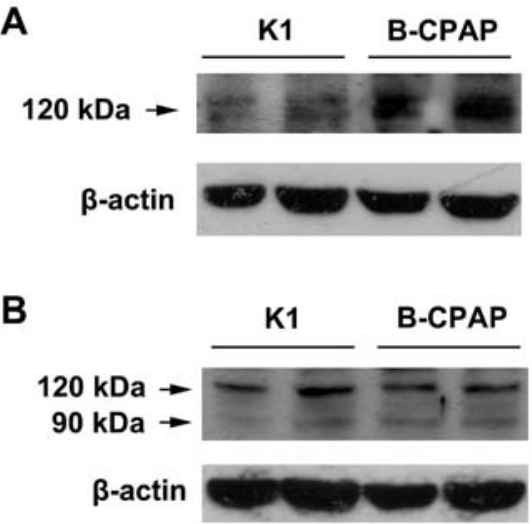

Figure 1. Leptin receptor protein expression was visualized in whole cell lysates of $\mathrm{K} 1$ and $\mathrm{B}-\mathrm{CPAP}$ cells by Western blotting with polyclonal antileptin receptor C-20 (A) and H-300 (B) antibodies. Equal loading and transfer were shown by repeat probing with $\beta$-actin.

Leptin does not influence cell growth of papillary thyroid cancer cells. $\mathrm{K} 1$ and B-CPAP cells were serum-starved and treated with serial doses of leptin. There was no significant change in cell growth (Fig. 2).

Leptin enhances cell migration of papillary thyroid cancer cells. Previously, we have demonstrated that leptin modulates thyroid cancer cell migration (23). To investigate our previous observation in these validated cell lines, migration of thyroid cancer cells was assessed using transwell migration assay after treatment with physiological concentrations of leptin $(5-125 \mathrm{ng} / \mathrm{ml})$ or vehicle. Leptin stimulated dose-dependent migration of K1 and B-CPAP cells (Fig. 3A). A significant stimulation was observed at a dose of $125 \mathrm{ng} / \mathrm{ml}$ in both cell lines. Consequently, we used this dose for the following experiments. These results were further verified using wound healing assay. The migratory ability of K1 and B-CPAP cells clearly increased in response to leptin treatment (Fig. 3B).

Leptin induces AKT and ERK phosphorylation in papillary thyroid cancer cells. We next investigated the leptin-induced intracellular signaling pathway in thyroid cancer cells. Because leptin-induced signaling have been reported to be mediated via the PI3K/AKT and mitogen-activated protein kinase (MAPK) signaling pathways (10-17), we examined whether leptin could induce AKT and ERK phosphorylation in K1 and B-CPAP cells. Total cellular proteins were extracted from cells treated with $125 \mathrm{ng} / \mathrm{ml}$ leptin for various time periods. The experiments showed that AKT and ERK phosphorylation was stimulated by leptin in a time-dependent fashion (Fig. 4). The levels of phosphorylated forms of AKT and ERK were increased as soon as $10 \mathrm{~min}$ after leptin treatment. Leptin had no effect on total ERK and AKT protein expression levels.

PI3K/AKT and MEK/ERK mediate leptin-induced cell migration. To clarify the role of PI3K/AKT and MAPK pathways

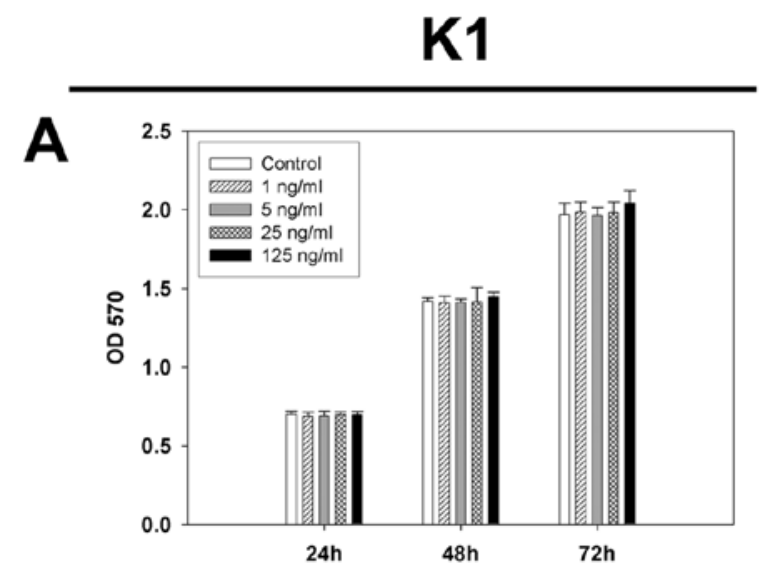

B-CPAP

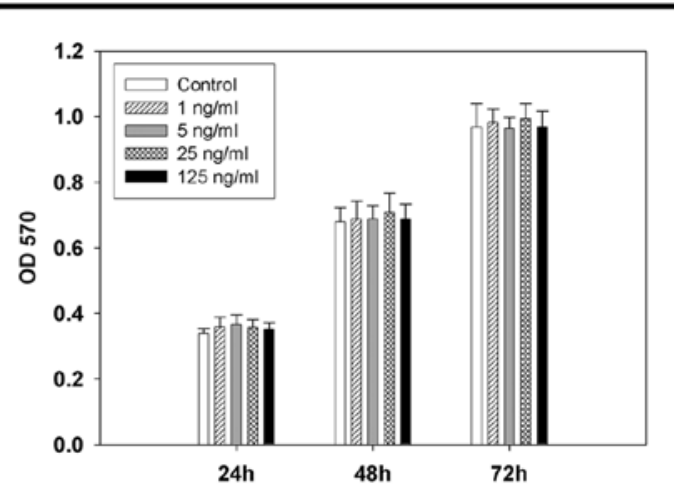

B
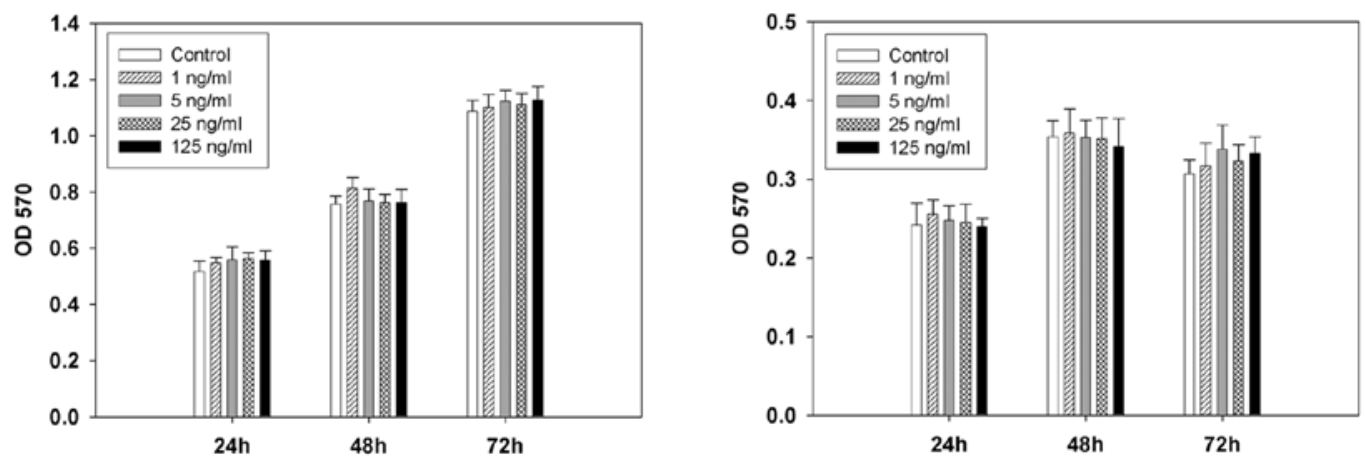

Figure 2. K1 and B-CPAP cells were seeded in 96-well plates, serum starved for $24 \mathrm{~h}$, and then incubated with serial doses of leptin as indicated in serumcontaining (A) or serum-free (B) media for 24-72 h. The cell growth was measured using MTT assay. 
K1

A

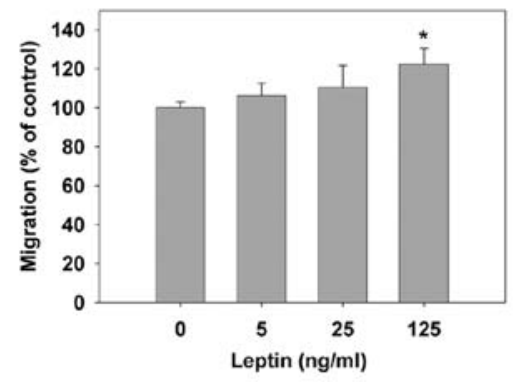

B

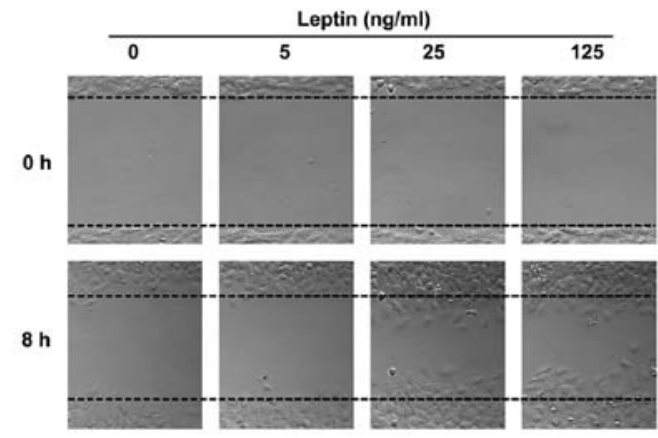

B-CPAP
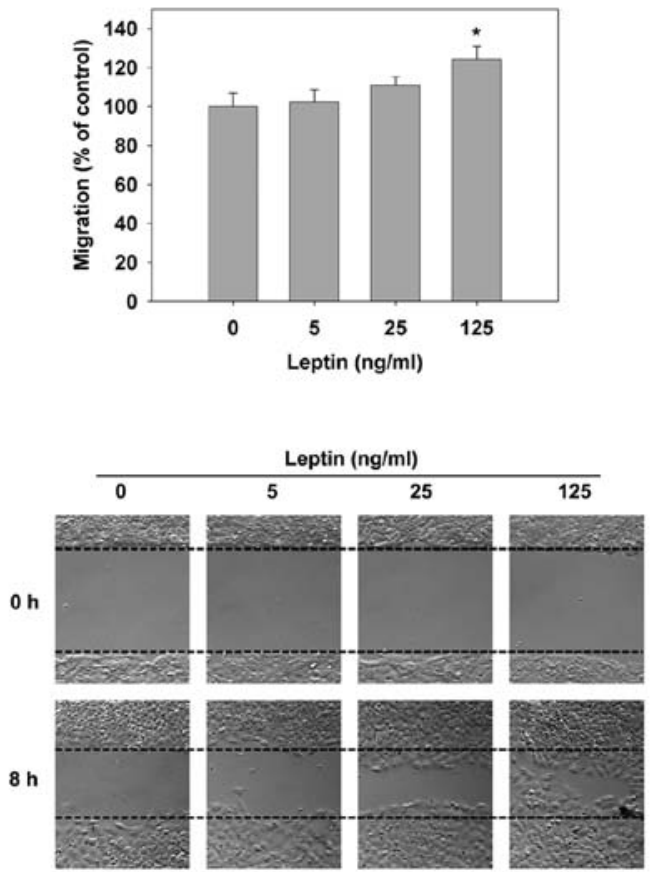

Figure 3. Effect of leptin on thyroid cancer cell migration. (A) K1 and B-CPAP cells were incubated in serum-free media containing different concentrations of leptin. At indicated time points, cells that had migrated to the bottom surface of the transwell membrane were counted. Data (mean \pm SEM) are representative of three to four independent experiments. "P<0.05, compared with control. (B) Confluent K1 and B-CPAP cells were incubated with serial concentrations of leptin and migrated across the gap. After $8 \mathrm{~h}$, cells were observed under microscopy and photographed. Each photograph represents an example of four randomly chosen areas from three to four separate experiments.
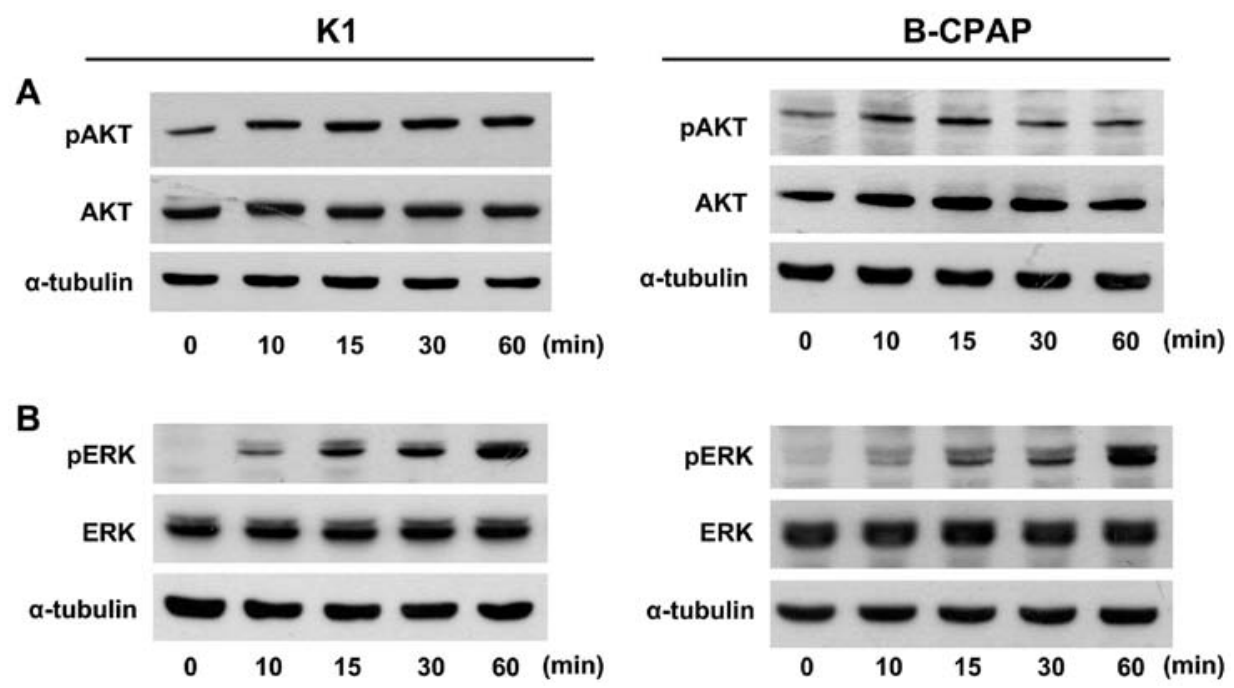

Figure 4. Leptin-induced activation of AKT and ERK in thyroid cancer cells. K1 and B-CPAP cells were serum-starved for $24 \mathrm{~h}$ and stimulated with leptin $(125 \mathrm{ng} / \mathrm{ml})$ for various time intervals. Time 0 represents untreated cells. Cell lysates were prepared and quantified for protein content. The status of active AKT (A) and ERK (B) was determined by Western blotting using specific antibodies against total or $\mathrm{Ser}^{473}$-phosphorylated forms of AKT, and total or Thr ${ }^{202 /}$ $\mathrm{Tyr}^{204}$-phosphorylated forms of ERK. The experiment was repeated at least three times with consistent results.

in leptin-induced cell migration, we used pharmacological inhibitors to determine the dependence of these signaling kinases on the migration-stimulating effect of leptin. As shown in Fig. 5A, pretreatment of K1 and B-CPAP cells with PI3K inhibitor LY294002 inhibited the phosphorylation of AKT protein without affecting the total AKT expression. As expected, pretreatment with MEK kinase inhibitor PD98059 blocked the leptin-induced ERK phosphorylation (Fig. 5B).

It was further examined whether these specific inhibitors prevent leptin-induced cell migration. Pretreatment with LY294002 or PD098059 significantly inhibited the migration capacity induced by $125 \mathrm{ng} / \mathrm{ml}$ leptin in $\mathrm{K} 1$ and B-CPAP cells 
K1

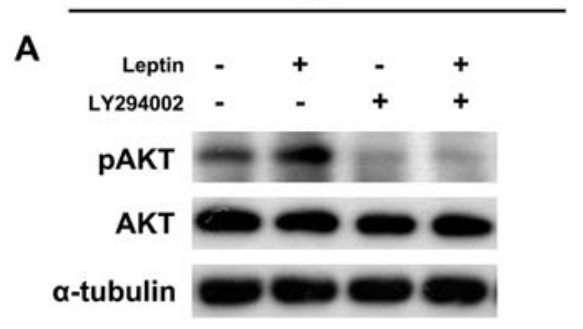

B

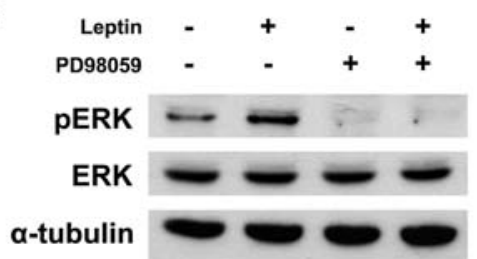

B-CPAP
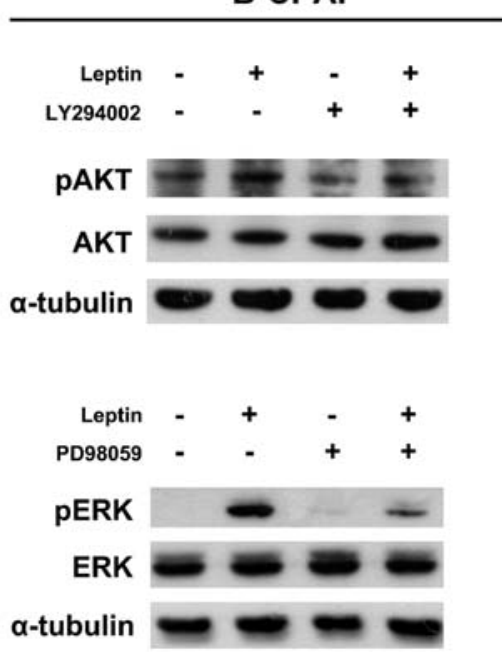

Figure 5. Leptin-induced AKT and ERK activation blocked by preincubation with corresponding inhibitors. K1 and B-CPAP cells were serum-starved for $24 \mathrm{~h}$ and treated with leptin $(125 \mathrm{ng} / \mathrm{ml})$ for $1 \mathrm{~h}$. For combined treatment, cells were pretreated with phosphoinositide 3-kinase inhibitor LY294002 (25 $\mu \mathrm{M})$ (A) or MEK kinase inhibitor PD98059 $(40 \mu \mathrm{M})$ (B) for $1 \mathrm{~h}$ followed by leptin treatment. Cell lysates were blotted with specific antibodies against total or $\mathrm{Ser}^{473}$-phosphorylated forms of AKT, and total or $\mathrm{Thr}^{202} / \mathrm{Tyr}^{204}$-phosphorylated forms of ERK.

K1

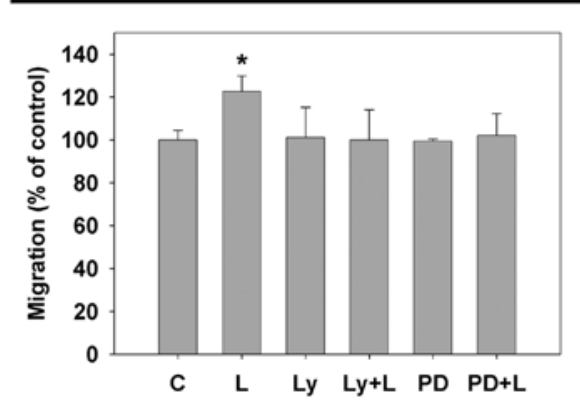

B-CPAP

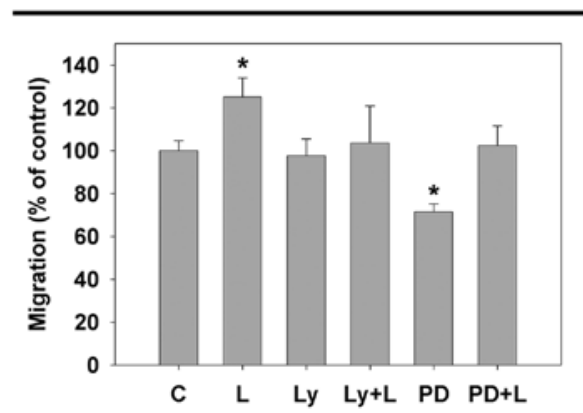

Figure 6. Modulation of leptin-induced migration in papillary thyroid cancer cells. K1 and B-CPAP cells were cultured in transwell chambers in serum-free media containing $125 \mathrm{ng} / \mathrm{ml}$ leptin (L). For combined treatment, cells were pretreated with $25 \mu \mathrm{M} \mathrm{LY} 294002$ (Ly+L) or $40 \mu \mathrm{M}$ PD98059 (PD+L) for $1 \mathrm{~h}$ followed by leptin treatment. After treatment with leptin for $8 \mathrm{~h}$ (K1) or $6 \mathrm{~h}$ (B-CPAP), number of cells that migrated through the transwell membrane was counted. Results are shown as relative mean \pm SEM of at least three independent experiments. ${ }^{*} \mathrm{P}<0.05$, compared with untreated control (C) cells.

(Fig. 6). Taken together, these results indicate that the increase of p-AKT and p-ERK levels play an important role in leptinstimulated cell migration in human papillary thyroid cancer cells.

\section{Discussion}

Leptin is an adipokine produced and secreted mainly by the adipose tissue in proportion to fat stores. Many adipokines and/or their receptors are now recognized to be expressed ectopically by cancer cells $(6,7)$. In turn, cancer cells may respond to adipokines in an endocrine, paracrine, or autocrine fashion. The mechanisms of altered expression of leptin and/ or leptin receptor in malignant tumors are still little known and might be related to the carcinogenesis process. Frequency of leptin expression dramatically increases from normal colonic mucosa to adenomas and adenocarcinomas along with neoplastic progression (25). Previously we have shown that leptin and leptin receptor are co-expressed in thyroid cancer tissues and cancer cells $(21,23)$, suggesting the possibility of autocrine/paracrine regulation. In obesity, adipose tissue hypoxia is an important factor in the development of inflammatory response, increased leptin and reduced adiponectin gene expressions (26). In breast cancer cells, leptin can be up-regulated in response to hypoxia or hyperinsulinemia $(27,28)$. The role of hypoxia in up-regulation of leptin receptor and/or leptin in thyroid cancer deserves further investigation.

We also found that the mechanism by which leptin mediated its effects on migration of thyroid cancer cells appears to involve the activation of PI3K/AKT and MAPK pathways. Aberrant activation of the PI3K/AKT and MAPK signaling pathways plays a fundamental role in thyroid tumorigenesis $(29,30)$. Apart from genetic alterations such as activating mutations of the $B R A F$ and $R A S$ genes, other upstream activators may also simulate these signaling in thyroid cancer. Liu et al (31) examined mutations and copy number gains of a large panel of genes in thyroid cancer, showing that most anaplastic $(90 \%)$ and follicular (86\%) cancer harbored at least one genetic 
alteration. Interestingly, phosphorylated AKT immunoreactivity without genetic alterations was identified in two cases. In another study of follicular variants of papillary thyroid cancer, two of the 30 tumors had ERK phosphorylation independent of gene mutation status that was studied (32). Therefore, although it is well known that some genetic alterations lead to PI3K/ AKT and MAPK activation in thyroid cancer, other factors, including leptin through leptin receptor, may also activate these pathways and participate in the pathogenesis of thyroid cancer.

This study revealed that leptin-stimulated migration of thyroid cancer cells depends on PI3K/AKT and MAPK pathways. This is in keeping with the observation of others (13-17). We and others have shown that papillary thyroid cancer with expression of leptin receptor and/or leptin is associated with the risk of nodal metastasis $(21,22)$. The same oncogenic signaling cascade initiating transforming events in thyroid cancer cells also sustains their motile and invasive properties (33). MAPK pathway has been shown to promote cell adhesion turnover, contributing to tumor cell motility and invasion (34). This may explain why papillary thyroid cancer with $B R A F$ mutations is more likely to be metastatic (35). In the present study, compared to vehicle control, MEK kinase inhibitor PD98059 directly suppressed migration of B-CPAP cells (Fig. 6). Furthermore, AKT is also a critical modulator of cell migration and invasion in thyroid cancer (36). Specific inhibition of AKT1 may reduce thyroid cancer cell migration in vitro (37). Collectively, these data support the important role of PI3K/AKT and MAPK pathways activated by leptin during thyroid cancer metastasis.

Although papillary thyroid cancer expressing leptin receptor and/or leptin is associated with larger tumor size $(21,22)$, this study does not support the hypothesis that leptin promotes cell proliferation in thyroid cancer. Uddin et al (22) demonstrated that leptin could stimulate cell proliferation and inhibit apoptosis in B-CPAP and $8505 \mathrm{C}$ cell lines via the activation of PI3K/AKT signaling pathway. However, we found that leptin had no effect on cell growth in B-CPAP and 8505C thyroid cancer cells (Fig. 2 and data not shown). The basis for such a difference is presently unclear. As for the discrepancy between tissue expression and cellular studies, it may be due to limitations of current cell-based models. Thyroid epithelial cells are highly polarized with distinct apical and basolateral regions (38). Monolayer cells grown in culture dishes lose the glandular structure and may not provide the optimal system for fully understanding the regulation of cell proliferation and interactions with microenvironment (39). Alternatively, a plausible explanation is the concept of self-seeding (40). Cells that disseminate from a tumor may circulate throughout the body and repopulate the tumor at distant sites. Therefore, although large tumor burden generally reflects an increased proliferation, abnormal cell mobility could also contribute to the tumor growth.

In conclusion, this study clearly provides the molecular mechanisms responsible for the leptin-stimulated migration of papillary thyroid cancer cells. Considering that thyroid cancer expressing leptin receptor and/or leptin has higher incidence of nodal metastasis, the identification of leptin-mediated signaling pathways offers a novel potential target for the management of papillary thyroid cancer.

\section{Acknowledgements}

This study was supported by research grants from Mackay Memorial Hospital (MMH-9867 and MMH-9946), Taipei Veterans General Hospital (V99C1-053) and Center of Excellence for Cancer Research at Taipei Veterans General Hospital (DOH99-TD-C-111-007).

\section{References}

1. Renehan AG, Tyson M, Egger M, Heller RF and Zwahlen M: Body-mass index and incidence of cancer: a systematic review and meta-analysis of prospective observational studies. Lancet 371: 569-578, 2008.

2. Wolin KY and Colditz GA: Can weight loss prevent cancer? Br J Cancer 99: 995-999, 2008.

3. Roberts DL, Dive C and Renehan AG: Biological mechanisms linking obesity and cancer risk: new perspectives. Annu Rev Med 61: 301-316, 2010.

4. van Kruijsdijk RC, van der Wall E and Visseren FL: Obesity and cancer: the role of dysfunctional adipose tissue. Cancer Epidemiol Biomarkers Prev 18: 2569-2578, 2009.

5. Ahima RS and Flier JS: Leptin. Annu Rev Physiol 62: 413-437, 2000.

6. Garofalo C and Surmacz E: Leptin and cancer. J Cell Physiol 207: 12-22, 2006.

7. Vona-Davis L and Rose DP: Adipokines as endocrine, paracrine, and autocrine factors in breast cancer risk and progression. Endocr Relat Cancer 14: 189-206, 2007.

8. Zhang Y, Proenca R, Maffei M, Barone M, Leopold L and Friedman JM: Positional cloning of the mouse obese gene and its human homologue. Nature 372: 425-432, 1994.

9. Tartaglia LA, Dembski M, Weng X, Deng N, Culpepper J, Devos R, Richards GJ, Campfield LA, Clark FT, Deeds J, Muir C, Sanker S, Moriarty A, Moore KJ, Smutko JS, Mays GG, Wool EA, Monroe CA and Tepper RI: Identification and expression cloning of a leptin receptor, OB-R. Cell 83: 1263-1271, 1995.

10. Chen C, Chang YC, Liu CL, Chang KJ and Guo IC: Leptininduced growth of human ZR-75-1 breast cancer cells is associated with up-regulation of cyclin D1 and c-Myc and downregulation of tumor suppressor p53 and p21WAF1/CIP1. Breast Cancer Res Treat 98: 121-132, 2006.

11. Chen C, Chang YC, Liu CL, Liu TP, Chang KJ and Guo IC: Leptin induces proliferation and anti-apoptosis in human hepatocarcinoma cells by up-regulating cyclin D1 and down-regulating Bax via a Janus kinase 2-linked pathway. Endocr Relat Cancer 14: 513-529, 2007.

12. Somasundar P, Frankenberry KA, Skinner H, Vedula G, McFadden DW, Riggs D, Jackson B, Vangilder R, Hileman SM and Vona-Davis LC: Prostate cancer cell proliferation is influenced by leptin. J Surg Res 118: 71-82, 2004.

13. Sharma D, Saxena NK, Vertino PM and Anania FA: Leptin promotes the proliferative response and invasiveness in human endometrial cancer cells by activating multiple signal-transduction pathways. Endocr Relat Cancer 13: 629-640, 2006.

14. Saxena NK, Taliaferro-Smith L, Knight BB, Merlin D Anania FA, O'Regan RM and Sharma D: Bidirectional crosstalk between leptin and insulin-like growth factor-I signaling promotes invasion and migration of breast cancer cells via transactivation of epidermal growth factor receptor. Cancer Res 68: 9712-9722, 2008.

15. Saxena NK, Sharma D, Ding X, Lin S, Marra F, Merlin D and Anania FA: Concomitant activation of the JAK/STAT, $\mathrm{PI} 3 \mathrm{~K} / \mathrm{AKT}$, and ERK signaling is involved in leptin-mediated promotion of invasion and migration of hepatocellular carcinoma cells. Cancer Res 67: 2497-2507, 2007.

16. Frankenberry KA, Somasundar P, McFadden DW and VonaDavis LC: Leptin induces cell migration and the expression of growth factors in human prostate cancer cells. Am J Surg 188: 560-565, 2004.

17. Jaffe $\mathrm{T}$ and Schwartz B: Leptin promotes motility and invasiveness in human colon cancer cells by activating multiple signal-transduction pathways. Int J Cancer 123: 2543-2556, 2008.

18. Chen AY, Jemal A and Ward EM: Increasing incidence of differentiated thyroid cancer in the United States, 1988-2005. Cancer 115: 3801-3807, 2009. 
19. Clavel-Chapelon F, Guillas G, Tondeur L, Kernaleguen C and Boutron-Ruault MC: Risk of differentiated thyroid cancer in relation to adult weight, height and body shape over life: the French E3N cohort. Int J Cancer 126: 2984-2990, 2010.

20. Akinci M, Kosova F, Cetin B, Aslan S, Ari Z and Cetin A: Leptin levels in thyroid cancer. Asian J Surg 32: 216-223, 2009.

21. Cheng SP, Chi CW, Tzen CY, Yang TL, Lee JJ, Liu TP and Liu CL: Clinicopathologic significance of leptin and leptin receptor expressions in papillary thyroid carcinoma. Surgery 147: 847-853, 2010.

22. Uddin S, Bavi P, Siraj AK, Ahmed M, Al-Rasheed M,Hussain AR, Ahmed M, Amin T, Alzahrani A, Al-Dayel F, Abubaker J, Bu R and Al-Kuraya KS: Leptin-R and its association with PI3K/AKT signaling pathway in papillary thyroid carcinoma. Endocr Relat Cancer 17: 191-202, 2010.

23. Cheng SP, Yin PH, Chang YC, Lee CH, Huang SY and Chi CW: Differential roles of leptin in regulating cell migration in thyroid cancer cells. Oncol Rep 23: 1721-1727, 2010.

24. Schweppe RE, Klopper JP, Korch C, Pugazhenthi U, Benezra M, Knauf JA, Fagin JA, Marlow LA, Copland JA, Smallridge RC and Haugen BR: Deoxyribonucleic acid profiling analysis of 40 human thyroid cancer cell lines reveals cross-contamination resulting in cell line redundancy and misidentification. J Clin Endocrinol Metab 93: 4331-4341, 2008.

25. Paik SS, Jang SM, Jang KS, Lee KH, Choi D and Jang SJ: Leptin expression correlates with favorable clinicopathologic phenotype and better prognosis in colorectal adenocarcinoma. Ann Surg Oncol 16: 297-303, 2009

26. Trayhurn P, Wang B and Wood IS: Hypoxia and the endocrine and signalling role of white adipose tissue. Arch Physiol Biochem 114: 267-276, 2008

27. Cascio S, Bartella V, Auriemma A, Johannes GJ, Russo A, Giordano A and Surmacz E: Mechanism of leptin expression in breast cancer cells: role of hypoxia-inducible factor-1alpha. Oncogene 27: 540-547, 2008.

28. Bartella V, Cascio S, Fiorio E, Auriemma A, Russo A and Surmacz E: Insulin-dependent leptin expression in breast cancer cells. Cancer Res 68: 4919-4927, 2008.

29. Knauf JA and Fagin JA: Role of MAPK pathway oncoproteins in thyroid cancer pathogenesis and as drug targets. Curr Opin Cell Biol 21: 296-303, 2009.

30. Saji M and Ringel MD: The PI3K-Akt-mTOR pathway in initiation and progression of thyroid tumors. Mol Cell Endocrinol 321: $20-28,2010$
31. Liu Z, Hou P, Ji M, Guan H, Studeman K, Jensen K, Vasko V, El-Naggar AK and Xing M: Highly prevalent genetic alterations in receptor tyrosine kinases and phosphatidylinositol 3-kinase/akt and mitogen-activated protein kinase pathways in anaplastic and follicular thyroid cancers. J Clin Endocrinol Metab 93: 3106-3116, 2008.

32. Santarpia L, Myers JN, Sherman SI, Trimarchi F, Clayman GL and El-Naggar AK: Genetic alterations in the RAS/RAF/mitogenactivated protein kinase and phosphatidylinositol 3-kinase/Akt signaling pathways in the follicular variant of papillary thyroid carcinoma. Cancer 116: 2974-2983, 2010.

33. Melillo RM, Castellone MD, Guarino V, De Falco V, Cirafici AM, Salvatore G, Caiazzo F, Basolo F, Giannini R, Kruhoffer M, Orntoft T, Fusco A and Santoro M: The RET/PTC-RAS-BRAF linear signaling cascade mediates the motile and mitogenic phenotype of thyroid cancer cells. J Clin Invest 115: 1068-1081, 2005.

34. Viala E and Pouyssegur J: Regulation of tumor cell motility by ERK mitogen-activated protein kinases. Ann N Y Acad Sci 1030: 208-218, 2004

35. Kim J, Giuliano AE, Turner RR, Gaffney RE, Umetani N, Kitago M, Elashoff D and Hoon DS: Lymphatic mapping establishes the role of BRAF gene mutation in papillary thyroid carcinoma. Ann Surg 244: 799-804, 2006.

36. Vasko V, Saji M, Hardy E, Kruhlak M, Larin A, Savchenko V, Miyakawa M, Isozaki O, Murakami H, Tsushima T, Burman KD, De Micco C and Ringel MD: Akt activation and localisation correlate with tumour invasion and oncogene expression in thyroid cancer. J Med Genet 41: 161-170, 2004.

37. Saji M, Vasko V, Kada F, Allbritton EH, Burman KD and Ringel MD: Akt1 contains a functional leucine-rich nuclear export sequence. Biochem Biophys Res Commun 332: 167-173, 2005.

38. Chambard M, Verrier B, Gabrion J and Mauchamp J: Polarization of thyroid cells in culture: evidence for the basolateral localization of the iodide 'pump' and of the thyroid-stimulating hormone receptor-adenyl cyclase complex. J Cell Biol 96: 1172-1177, 1983.

39. O'Brien LE, Zegers MM and Mostov KE: Opinion: Building epithelial architecture: insights from three-dimensional culture models. Nat Rev Mol Cell Biol 3: 531-537, 2002.

40. Kim MY, Oskarsson T, Acharyya S, Nguyen DX, Zhang XH, Norton L and Massague J: Tumor self-seeding by circulating cancer cells. Cell 139: 1315-1326, 2009. 